\title{
Degradation of stone materials in the Greek-Roman Hadrianic Baths in Leptis Magna (Libya)
}

\section{Dr.Nabil A. Abdeltawab}

\section{$\underline{\text { Abstract: }}$}

Hadrianic Baths is one of the important Archaeological Sites in Leptis Magna-Libya. It was Built by the command of Emperor Hadrian in the early 2 nd century CE, these represent some of the most lavish structures of Leptis Magna. It is unique in design and building technique where it was built of limestone and marble. The baths contained an open-air swimming pool, and several indoor pools, both with hot water and cold. Furnaces used for heating water are found outside the southern walls. Also note the several small rooms, these were changing cabinets, and the latrine with marble seats. Entrance to the baths are through the sports ground.

The Hadrianic Baths is subjecting to the sever action due to the climate which is typically marine. This site suffer from different weathering forms, for example honeycomb, disintegration between grains, pitting, missing parts, cracks, erosion and efflorescence salts. Many deterioration factors were caused this weathering forms such as source of moisture, salt weathering, biological and microbiological weathering, change in temperature and wind erosion. The aim of this study is to characterize the building materials at Hadrianic Baths which suffering from server weathering forms specialty honeycomb and biological weathering.

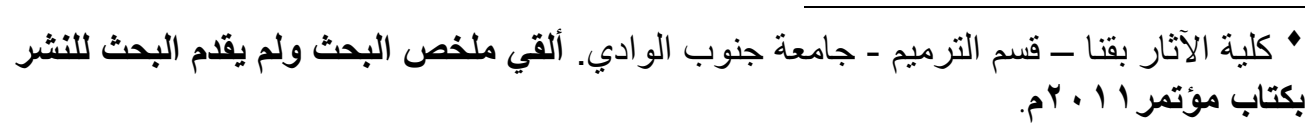

